\title{
Los partidos de entrenamiento en el tenis femenino (Parte 2)
}

\author{
Jean-Luc Cotard \\ Federación Francesa de Tenis, Francia \\ RESUMEN
}

A través de la experiencia, he aprendido que las sesiones de "confrontación" con una alta carga emocional, cuando las niñas son muy jóvenes, requieren grandes habilidades pedagógicas. Mi objetivo en este artículo es, a partir de los testimonios de jugadoras y entrenadores, evaluar objetivamente el juego de partidos durante el entrenamiento.

\author{
Palabras clave: femenino, \\ habilidades, partido de tenis, \\ entrenamiento. \\ Recibido: 13 Octubre 2017 \\ Aceptado: 25 Enero 2018 \\ Autor correspondiente: \\ Jean-Luc Cotard. Federación \\ Francesa de Tenis, Francia \\ Correo electrónico: \\ jlcotard@fft.fr
}

\section{VEAMOS AHORA LO QUE DICEN LOS ENTRENADORES}

\section{Testimonio No. 1.}

"No son lo suficientemente lúdicos".

"No están lo suficientemente listas para correr riesgos".

"Su criterio tiende a basarse en el paradigma ganar-perder".

"Es fundamental explicar, no juzgar. Aprender a encontrar las soluciones, descubrir las debilidades de la adversaria. Comprender en qué dirección quieres ir, progresar". Eso está todo muy bien, pero ¿en qué momento entra en juego la noción de temor?

"Es necesario sugerir diferentes formatos de juego, partidos basados en temas específicos, como para que la jugadora no sienta que está jugando un partido real".

Comentario de un entrenador que comprende que la mente juega un gran rol, especialmente en un deporte de oposición como el tenis.

"Como regla general, a las niñas no les gusta practicar entre ellas. Es mejor hacer que jueguen con los niños. Esto es particularmente cierto entre las mejores jugadoras, ¡incluyendo a las extranjeras!".

Hace que todo el concepto del juego de partidos carezca de significado: las jugadoras juegan asegurándose de que no sean partidos reales.
Esto se puede hacer, pero debes saber lo que estás haciendo, y cuándo hacerlo.

\section{Testimonio No. 2.}

"Ya sea con o sin instrucciones durante la práctica, no hay nada como la competición, jugar partidos reales. No generemos expertos en partidos de entrenamiento".

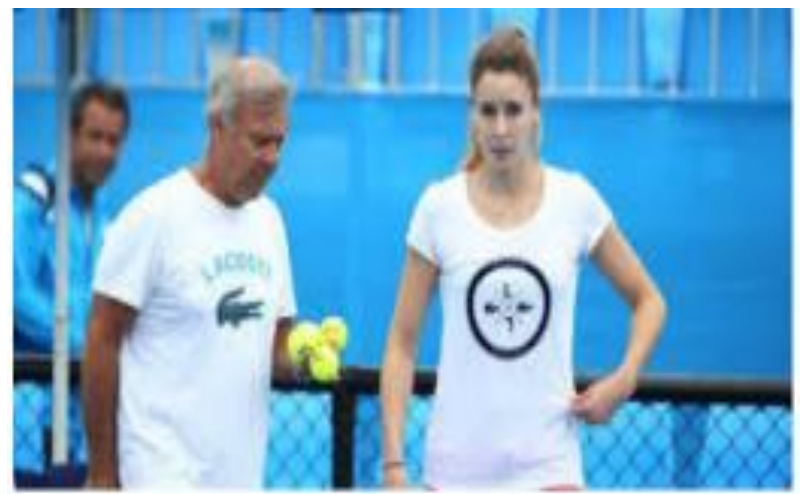

"Cuando era capitán del equipo de Fed Cup, si yo decidía que mis dos mejores jugadoras jugaran un partido de entrenamiento entre sí, y la mejor perdía, inmediatamente había perdido tanto a la jugadora número 1 (pérdida de confianza) como a la número 2 (exceso de confianza)".

Aquí, el tema no es el partido de entrenamiento en sí, en todo caso, debes saber cuándo utilizarlo y con quién. 


\section{Testimonio No. 3.}

"Abordemos los partidos (de entrenamiento) como punto de partida, una evaluación individual".

"Utilizando una evaluación bien pensada, puedes enseñar muchísimo".

"Necesitan aprender a perder, es parte de la vida en grupo".

"El partido es una oportunidad, proporciona un encuadre que va más allá del paradigma ganar-perder".

"Es esencial salir de la zona de confort".

"Es importante no hacer comparaciones, mantener su autoestima y no considerarlas como niñas pequeñitas".

"Las jugadoras necesitan divertirse poniendo en práctica lo que han estado trabajando".

"La confianza interior no está relacionada con el rendimiento. Hay que destruir algunas creencias".

"Entrenar a cada jugadora como si fuese la número uno".

Palabras que esperarías de un entrenador.

En base a estos testimonios, tratemos de definir las pautas metodológicas. Ser objetivo, evaluar manteniendo una actitud positiva, desarrollar la auto-estima, adquirir destrezas nuevas. Nada se compara con la realidad. Las preguntas que debemos formularnos son: ¿Qué estamos tratando de lograr con este ejercicio de simulación? ¿Qué efecto (positivo o negativo) tiene el resultado de un partido de entrenamiento sobre la deportista y su entrenador?

En general, los entrenadores y las jugadoras de alto nivel están a favor del juego de partidos durante el entrenamiento, por lo tanto, es importante encontrar el equilibrio correcto.

Lo que es particularmente notable cuando leemos los testimonios, es que muchas jugadoras dicen que los partidos de entrenamiento son estresantes pero que sólo son realmente importantes los partidos oficiales. Bastante extraño, ¿no te parece?

Algunas hasta llegan a decir, no siempre de manera explícita, que estos partidos no cumplen ningún propósito, pues son estresantes. Pero ese es el tema, ¿verdad? Esto es todo muy extraño

\section{PROPUESTAS METODOLÓGICAS}

La clave consiste en abordar el juego de partido por lo que realmente es, una oportunidad de confrontar las emociones.

Sabemos que los caminos de los neurotransmisores son diferentes dependiendo de la situación, es decir, si la jugadora está jugando un partido oficial o un partido de entrenamiento. Por lo tanto, se puede sugerir que los partidos de entrenamiento solamente sirven para entrenar los caminos neuronales que son específicos para... ¡los partidos de entrenamiento! En consecuencia, la repetición de esta situación podría trivializar la confrontación de la jugadora con sus emociones, y así, minimizar las estrategias utilizadas para manejarlas. Suponiendo que los partidos de entrenamiento carecen de significado, en lo que atañe a confrontar emociones, entonces, jugar estos partidos se torna inútil.

La simulación sigue siendo un modo excelente de preparar a las jugadoras para la ejecución "oficial", siempre y cuando el estrés esté presente, o sea incrementado artificialmente. Sin embargo, las jugadoras estarán estresadas solamente si la situación, o sea, el partido de entrenamiento, es excepcional. El peligro con las" rutinas ordinarias" es que el resultado puede no interesar. Crear situaciones excepcionales de alto estrés, permitir la revisión y la retroalimentación de la preparación, asegurarse de que los jugadores no sufran de heridas narcisistas: el foco debe colocarse en cosas concretas.

Simplemente decidir que se deben jugar partidos todos los días, o dos veces por semana, pues es lo que se hace en las "academias", parece no tener sentido.

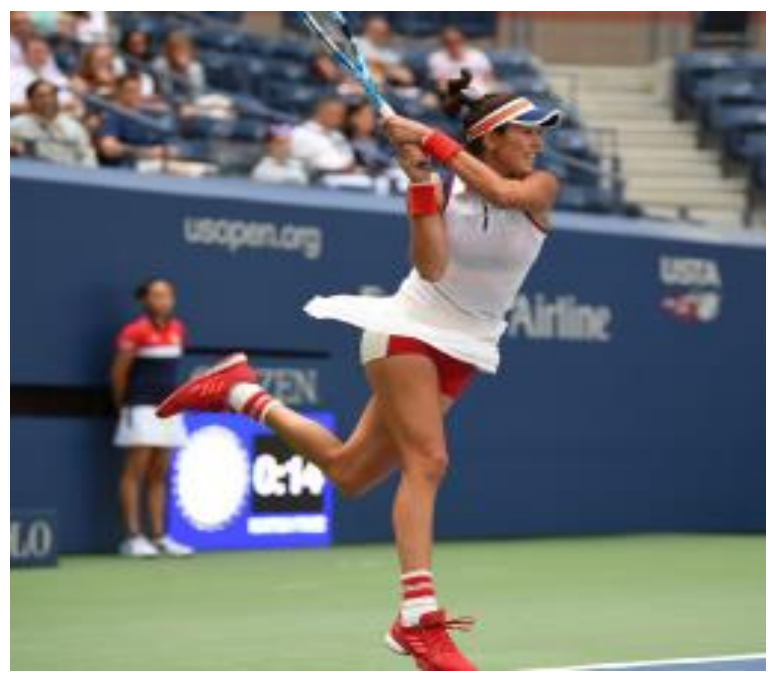

Nuestro objetivo es asegurar que los partidos de entrenamiento no se transformen en lesiones narcisistas.

Lo que llama más la atención a partir de los testimonios compilados, es que cuanto más alto es el nivel del jugador entrevistado en el circuito profesional, menor es la influencia de los partidos de entrenamiento sobre sus egos en el nivel juniors, como si la confianza interna no se viera afectada negativamente por el rendimiento durante el entrenamiento.

Esto resulta interesante pues muy frecuentemente, como entrenadores, esperamos que nuestros jugadores desplieguen una actitud luchadora en cancha durante los partidos de entrenamiento. En tales casos, inconscientemente, consideramos que los partidos de entrenamiento no son una herramienta sino ¡una respuesta (aún un perfil psicológico)! Los entrenadores que no saben, esperan una respuesta, mientras que los que están en duda, buscan una solución. Uno podría argumentar que las futuras mejores jugadoras poseen, 
desde muy temprana edad, la habilidad de poner las cosas en perspectiva y diferenciar entre la competición de entrenamiento y la oficial. ¿Debería tenerse en cuenta este tipo de actitud indiferente y despreocupada durante la identificación del talento? En cambio, según su entrenador anterior, una jugadora, reciente número uno, se negó a practicar con otra jugadora, y solamente quería sparrings varones para sus partidos de entrenamiento.

Todo esto para decir que este tema es bastante más complejo de lo que parece. Los partidos no son una respuesta, sino una herramienta, que requiere habilidades y que no debe dejarse de lado.

Es, por lo tanto, necesario diferenciar los objetivos para poder:

1- Fijarlos;

2- Observarlos y cuantificarlos;

3- Revisarlos y analizarlos cualitativa y cuantitativamente.

Entonces, es necesario considerar 5 categorías diferentes de partidos:

- Partidos para mejorar el control de las emociones (fallos equivocados, público hostil, sistemas de recompensas/ penalidades en base al resultado del partido)

- Partido para mejorar la claridad mental (ella está en una buena posición), yo no lo estoy, ¿cómo puedo cambiar el momento?, no puedo ganar, ¿pero puede ella perder?

- Un partido para trabajar sobre aspectos muy específicos (porcentaje de primeros servicios, trabajo de pies, recuperación, etc.)

- Partido para trabajar las habilidades tácticas (tener en cuenta al adversario)

- Partido para trabajar las estrategias (identificar los puntos importantes, los momentos decisivos, etc.).

\section{CONCLUSIÓN}

La programación de los partidos de entrenamiento no es una tarea fácil. Es necesario pensar mucho y comprender el "por qué", el "qué", y el "cómo", para que la sesiones se puedan transferir de manera efectiva a los partidos "reales". Por lo tanto, debe verse como una sesión para evaluar las habilidades técnicas y conductuales durante las cuales surgirán todo tipo de emociones, las cuales, a su vez, desencadenarán las reacciones biomecánicas y ambientales. Enfrentado con este estado de conciencia emocional, el entrenador hará uso de todas las herramientas disponibles para, "vender el partido de entrenamiento" como un momento excepcional y raro. El objetivo deberá seleccionarse cuidadosamente para que el entrenador pueda observar y revisar cada sesión de manera constructiva y sin hacer juicios.
Un partido de entrenamiento nunca será lo mismo que un partido oficial. Si ese es el caso, ¿puede ser cierto lo contrario? ¿Es posible entrenar los neurotransmisores para que sigan solamente un camino, hacia la búsqueda del rendimiento óptimo, ya sea en competición de entrenamiento u oficial?

El autor desearía agradecer a las siguientes personas por sus valiosísimas contribuciones para este artículo:

Amélie MAURESMO (ex jugadora No. 1 de la WTA)

Alizé CORNET (mejor ranking de la WTA, No. 11)

Alexandra FUSAI (ex -jugadora de la WTA, No. 37)

Émilie LOIT (ex jugadora de la WTA, No. 27)

Magdalena MALEEVA (ex No. 4 de la WTA)

Pauline PARMENTIER (mejor ranking de la WTA, No. 40)

Anne-Gaëlle SIDOT (ex -jugadora de la WTA, No. 24)

Fiona FERRO (mejor ranking de la WTA, No. 247)

Mathilde ARMITANO (mejor ranking de la WTA, No. 1028)

Loöc COURTEAU (ex entrenador de Amélie Mauresmo)

Georges GOVEN (ex entrenador de Alizé CORNET, actual entrenador de K. MLADENOVIC)

Sam SUMYK (ex entrenador de V. AZARENKA, E. BOUCHARD, actual entrenadora de G. MUGURUZA)

Jean SENGES (preparador físico principal, CREPS de SaintRaphäel)

Erik MALENFANT (preparador físico, FFT, CNS de SaintRaphaël)

Enzo PY (estudiante de periodismo)

CONTENIDO ITF ACADEMY RECOMENDADO (HAZ CLICK ABAJO)

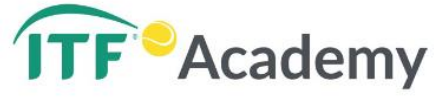

Derechos de Autor (c) 2018 Jean-Luc Cotard

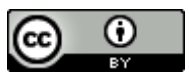

Este texto está protegido por una licencia CreativeCommons 4.0 .

Usted es libre para Compartir -copiar y redistribuir el material en cualquier medio o formato- y Adaptar el documento -remezclar, transformar y crear a partir del material- para cualquier propósito, incluso para fines c omerciales, siempre que cumpla la condición de:

Atribución: Usted debe dar crédito a la obra original de manera adecuada, proporcionar un enlace a la licencia, e indicar si se han realizado cambios. Puede hacerlo en cualquier forma razonable, pero no de forma tal que sugiera que tiene el apoyo del licenciante o lo recibe por el uso que hace de la obra.

$\underline{\text { Resumendelicencia - Textocompletodelalicencia }}$ 